\title{
Ecological Validity of Expressed Emotion in Early Psychosis
}

\section{Lídia Hinojosa-Marqués ${ }^{1}$, Tecelli Domínguez-Martínez ${ }^{2}$, Thomas R. Kwapili ${ }^{3}$ and Neus Barrantes-Vidal ${ }^{1,4,5 *}$}

\begin{abstract}
'Departament de Psicologia Clínica i de la Salut, Universitat Autònoma de Barcelona, Barcelona, Spain, ${ }^{2}$ Centro de Investigación en Salud Mental Global, Dirección de Investigaciones Epidemiológicas y Psicosociales, Instituto Nacional de Psiquiatría "Ramón de la Fuente Muñiz", Mexico City, Mexico, ${ }^{3}$ Department of Psychology, University of Illinois at Urbana-Champaign, Champaign, IL, United States, ${ }^{4}$ Departament de Salut Mental, Sant Pere Claver-Fundació Sanitària, Barcelona, Spain, ${ }^{5}$ Centre for Biomedical Research Network on Mental Health (CIBERSAM), Instituto de Salud Carlos III, Barcelona, Spain
\end{abstract}

Expressed emotion (EE) is an aspect of the family environment that influences the course of multiple forms of psychopathology. However, there is limited research about how EE dimensions [i.e., criticism and emotional over-involvement (EOI)] are expressed in real-world settings. The present study used experience sampling methodology to investigate: 1) the criterion and construct validity of daily-life, momentary measures of criticism and EOI, and

\section{OPEN ACCESS}

Edited by:

Neeltje EM Van Haren, Erasmus University Rotterdam, Netherlands

Reviewed by:

Maria Semkovska, University of Limerick, Ireland John RE Fox, Cardiff University, United Kingdom

${ }^{*}$ Correspondence: Neus Barrantes-Vidal neus.barrantes@uab.cat

Specialty section: This article was submitted to Psychopathology, a section of the journa

Frontiers in Psychiatry

Received: 15 May 2019 Accepted: 30 October 2019 Published: 21 November 2019

Citation: Hinojosa-Marqués L, Domínguez-Martínez T, Kwapil TR and Barrantes-Vidal N (2019) Ecological Validity of Expressed Emotion in Early Psychosis.

Front. Psychiatry 10:854. doi: 10.3389/fpsyt.2019.00854
2) the construct and ecological validity of psychometric EE-dimensions as assessed with the self-report Family Questionnaire (FQ). A total sample of 55 relatives (34 relatives of at-risk mental state patients and 21 of first-episode psychosis patients) were prompted randomly six times daily for 1 -week to assess their current emotional experiences and cognitive appraisals. Relatives also completed the FQ. Momentary criticism and EOI were significantly associated with the two FQ-EE dimensions respectively, supporting the criterion validity of real-world assessed EE dimensions. As hypothesized, momentary and FQ-EE dimensions were associated with decreased positive affect, as well as with appraisals of less effective coping in daily life. Only momentary EE dimensions were associated with increased momentary negative affect. Partly in contrast with our hypotheses, momentary criticism and FQ-criticism were more consistently related to situational stress and burden than momentary EOI and FQ-EOI. Finally, neither momentary nor FQ-EE dimensions showed distinct patterns of associations with illness attributions. Findings partly support the construct validity of momentary criticism and $\mathrm{EOI}$ as well as the construct and ecological validity of the FQ as a sensitive measure of EE dimensions.

Keywords: experience sampling, criticism, emotional over-involvement, early psychosis, family environment

\section{INTRODUCTION}

The prognostic value of factors identified in the early stages of psychosis $(1-3)$ has renewed the interest in environmental stressors as co-participating factors in the risk, onset, expression, and progression of psychosis (4-7). One of the most significant factors in psychosocial research in psychosis has been expressed emotion (EE) (8), a measure of the family environment used to describe relatives' attitudes toward an ill family member. High-EE attitudes, particularly criticism and emotional over-involvement (EOI), have been considered the strongest psychosocial predictor of relapse in schizophrenia (9-11). 
Although most studies on EE have been carried out in patients with chronic psychotic disorders $(12,13)$, recent research has focused on the study of EE in the early stages of the disorder $(14,15)$, in order to improve the understanding of the early development of high-EE and the problematic associated outcomes. Increasing evidence suggests that relatives of patients with first-episode of psychosis (FEP) and at-risk mental state (ARMS) often report high-EE levels (16-19). Moreover, relatives of patients with early psychosis often report high levels of burden, distress, depression, and anxiety related to high levels of EE (2024). Specifically, there is converging evidence suggesting that EOI is more related to distress and burden than criticism (17, 25-28). Given the large variety of negative outcomes associated with high-EE, both for relatives and patients, it is crucial to examine the psychological underpinnings of EE in early psychosis without the bias created by the chronic course of the illness and relatives' long-term burden.

The attributional model of EE posits that relatives' beliefs about the causes of the patients' illness are linked to relatives' emotional attitudes toward patients (29). It seems that critical relatives are more likely to perceive symptoms as controllable by patients, even at recent-onset psychosis stages $(30,31)$. Consequently, they attempt to reduce the undesired behaviors through critically persuading or coercing the patient. In contrast, overinvolved relatives tend to attribute symptoms to external factors that are beyond the patients' control $(32,33)$. However, they may also perceive patients' symptoms under their own control (34) and even can report high levels of guilt and/ or self-blame attributions $(35,36)$. This in turn makes them more likely to exhibit intrusive and/or self-sacrificing attitudes. An alternative explanatory model of EE proposes that high-EE attitudes may represent a maladaptive attempt to cope with the stress of caring for an impaired ill relative; thus, EE behaviors could be deemed as maladaptive coping strategies used to reduce the perceived stress related to the caregiving role (25, 37). In fact, relatives of patients with schizophrenia with high EE perceive their ability to cope as less effective and more impaired than those with low-EE (38). Also, emotion-focused strategies, such as avoidant coping, have been related to high-EE attitudes in relatives of FEP patients $(22,37)$.

Few studies have examined EE in early psychosis patients, and these have typically relied on retrospective reports. Furthermore, the vast majority of studies have not considered how EE is displayed within the natural family environment. This is a limitation given that EE is conceptualized within an interactional framework $(12,39,40)$. Therefore, it is crucial to examine how $\mathrm{EE}$ is expressed within the contexts of relatives' interactions with patients and in relation to daily appraisals and caregivers' subjective states in real-world settings.

The construct and ecological validity of $\mathrm{EE}$ has been supported by research showing that high-EE relatives tend to be more critical and intrusive in their direct transactions with patients than low-EE relatives (41-43). However, most studies have assessed family interactions as a function of global EE, without considering that criticism and EOI involve different underlying appraisals and may be associated with differential patterns of behaviors (44-46). Specifically, relatives high on the criticism dimension manifest critical attitudes at a behavioral level (47-49) and tend to offer demeaning statements in parentpatient interactions (50). However, findings supporting the construct validity of EOI have been less consistent $(50,51)$. Some studies indicate that high-EOI relatives make intrusive (52) or ambiguous statements (53), whereas others report that they exhibit high rates of positive and supportive statements in interaction studies (54). These studies offer valuable information of the behavioral correlates of $\mathrm{EE}$ in laboratory settings. However, as these paradigms focus on objectively defined family interactional tasks (e.g., interactions lasting $10 \mathrm{~min}$ or longer), they are unable to capture how EE components are expressed in daily life and relate to the wide variety of caregiver's subjective states within the natural family environment.

Unlike previous research, the current study employed experience sampling methodology (ESM) to examine the daily life expression of EE. ESM provides several benefits compared to conventional laboratory or clinic-based assessment paradigms (e.g., 55): 1) it enhances ecological validity because it allows to evaluate participants in their daily environment, 2) it captures participant's experience in the moment, thus minimizing retrospective bias, and 3) allows for an examination of the context in which the experience is occurring. To the best of our knowledge, the only study that has used an ecologically valid methodology to examine family interactions reported that relatives' high-EE status did not influence relatives' affect when relatives were in contact with patients (56). Although this work provided an ecologically valid insight on EE dynamics, it did not specifically measure the expression of EE dimensions in daily life.

Therefore, the general purpose of this study was to test the ecological validity of the criticism and EOI dimensions in a sample of relatives of early psychosis patients. To this end, the first aim of the current study was to analyze the criterion validity of momentary criticism and EOI (i.e., as measured with ESM) by examining their association with the EE-dimensions of the Family Questionnaire (FQ) (57), a widely used psychometric measure of EE. Regarding this first aim, it was predicted that the analogous momentary and psychometric indicators of criticism and EOI would be significantly and more strongly related to each other than to the other dimension.

The second aim was to examine the construct validity of momentary criticism and EOI, as well as the construct and ecological validity of psychometric EE dimensions by examining their associations with emotional, cognitive, and interpersonal behaviors occurring in the flow of daily life. We expected that momentary and psychometric criticism and EOI would show both common and distinctive correlates:

- Both EE dimensions (momentary and psychometric) were expected to be related to increased negative affect and decreased positive affect, appraisals of less effective coping, and momentary reports of increased situational stress and burden.

- Based on the attributional model of EE, different correlates were expected for criticism and EOI in relation to illness attributions. Momentary and FQ-criticism were predicted to be associated with attributions of control toward the patient, whereas momentary 
EOI and FQ-EOI were expected to be related to attributions of personal control over the disorder in daily life.

Additionally, we explored whether criticism and EOI, as measured by momentary and psychometric self-reports, showed differential associations with negative and positive appraisals about the self, positive appraisals about the patient, as well as with negative and positive appraisals about patients' behaviors in situations of direct and/or recent contact with the patient. Given the paucity of previous research the following hypotheses were exploratory. It was expected that high criticism would be related to negative appraisals about the patient, whereas EOI would show some associations with positive appraisals of the patient.

\section{MATERIALS AND METHODS}

\section{Participants and Procedure}

The present study is embedded in a larger longitudinal study carried out in three Mental Health Centres in Barcelona (Spain) within the Sant Pere Claver-Early Psychosis Program (SPC-EPP) (58). A total of 55 relatives of early psychosis patients (34 from ARMS and 21 from FEP patients), recruited in the SPC-EPP, were included in this study. An additional six participants were enrolled in the study and completed the questionnaires but were omitted from the analyses due to failing to complete the ESM protocols.

Relatives were referred to the study by their respective affected family members (i.e., early psychosis patients who were already participating in the study). Patients were informed of the relatives' study and asked to name the person to whom they have a significant/close relationship. After getting the consent of the patient, the relative was contacted and was asked to participate into the study. The recruited relatives were those who had the most regular contact and/or the most significant relationship with the patient. Relatives were predominantly female $(67.3 \%)$, specifically patients' mothers (63.6\%), with the remaining caregivers being fathers (25.5\%), partners, or siblings $(11 \%)$. Mean age of the relatives was 50.7 years old $(S D=8.96)$. Most relatives lived with the patient (85.5\%). Participants completed an average of $28.5(S D=11.4)$ usable ESM questionnaires $(67.8 \%)$.

Patients had to meet ARMS criteria as assessed by the Comprehensive Assessment of At-Risk Mental States (CAARMS) (59) and/or the Schizophrenia Proneness Instrument AdultVersion (SPI-A) (60). FEP patients met DSM-IV-TR criteria (61) for any psychotic disorder or affective disorder with psychotic symptoms as established by the Structured Clinical Interview for DSM-IV (SCID-I) (62). All relatives provided written informed consent to participate. The project was developed in accordance with the Code of Ethics of the World Medical Association (Declaration of Helsinki). Ethical approval for the study was obtained from the local ethics committee.

\section{Measures}

Relatives completed the FQ (57), a well-established instrument to measure EE. The FQ which consists of two 10-item subscales (criticism and EOI), with items answered on a four-point scale ranging from "never/very rarely" to "very often." The internal consistency (Cronbach's alpha) of the scores for the subscales in our sample was good, 0.89 for criticism and 0.86 for EOI.

ESM data were collected with personal digital assistants [PDAs; $\mathrm{n}=16(29 \%)]$, digital wristwatch and booklet $[\mathrm{n}=25(45 \%)]$, and mobile devices $[\mathrm{n}=14(26 \%)]$. The response rates (percentage of completed ESM questionnaires) did not significantly differ among the three methods employed, which were, respectively, 56.4, 75.9, and $66.8 \%(\mathrm{~F}=2.69 ; p=0.077)$. Note that numerous studies indicate that these methods produce comparable data in terms of quantity and quality $(63,64)$. Participants were signaled randomly six times daily (between 11 a.m. and 22 p.m.) for 1 week to complete brief questionnaires. When prompted by the signal, the participants had 5 min to initiate responding. After this time interval or the completion of the questionnaire, the PDA or mobile device became inactive until the next signal. Each questionnaire required $2 \mathrm{~min}$ to complete. All ESM items were answered on seven-point scales ranging from "not at all" to "very much," except for three yes/no items ("Are you with he/she right now?" "Since the last beep, did you have contact with he/she," "Right now, I wish he/she was here").

The ESM questionnaire included items that inquired about the following domains: 1) momentary criticism; 2) momentary EOI; 3) affect in the moment; 4) appraisals of effective coping; 5) appraisals about the current situation; 6) appraisals of burden; 7) illness attributions; 8) appraisals related to the self; 9) positive appraisals about the patient; and 10) a variety of appraisals that are only prompted if there is direct and/or recent contact with the patient. The ESM items inquiring about "appraisals in situations of direct and/or recent contact with the patient" were only administered when relatives endorsed either of the items: "Are you with he/she right now?" or "Since the last beep, did you have contact with he/ she." The rest of the ESM items were always administered.

The momentary criticism index was created using the following 4 items: "I feel exhausted by (the patient)," "I feel disappointed by (the patient)," "I feel angry with (the patient)," and "It is difficult to deal with (the patient)" (Cronbach's $\alpha=0.83$ ). Momentary EOI was assessed with the item "I am worried about (the patient)." Momentary EE items were developed on the basis of construct definitions and the items of the FQ (57). Summary indices were also computed for negative affect (NA) (Cronbach's $\alpha=0.81$ ), positive affect (PA) (Cronbach's $\alpha=0.87$ ), and relatives' positive appraisals about patients' behaviors in situations of direct and/ or recent contact with the patient (Cronbach's $\alpha=0.81$ ). Table 1 displays the ESM items and indices.

\section{Statistical Analysis}

Pearson correlations were computed to explore the association of momentary EE constructs (i.e., criticism and EOI) with psychometric EE dimensions (FQ) using the Statistical Package for Social Sciences (SPSS), Version 22.0. The effect size of the correlations was interpreted following Cohen's (65) guidelines (correlations of 0.10 indicate small effect sizes, 0.30 indicate medium effect sizes, and 0.50 indicate large effect sizes).

The statistical analyses involving the ESM data were conducted with Mplus 6 (66) ESM data have a multilevel structure in which ESM ratings (level 1 data) are nested within participants (level 2 data). Multilevel or hierarchical linear modeling techniques are 
TABLE 1 | Relatives' ESM questionnaire and summary indices.

\begin{tabular}{|c|c|}
\hline Questionnaire & Summary indices \\
\hline \multicolumn{2}{|l|}{ 1. Right now, I feel happy. } \\
\hline 2. Right now, I feel sad. & $\begin{array}{l}\text { Indices are computed as the means } \\
\text { of the items indicated. }\end{array}$ \\
\hline $\begin{array}{l}\text { 3. Right now, I feel I can cope with things } \\
\text { well. }\end{array}$ & $\begin{array}{l}\text { Momentary criticism: } 20,21,22 \text {, } \\
\text { and } 24\end{array}$ \\
\hline $\begin{array}{l}\text { 4. Right now, it is difficult to concentrate } \\
\text { or make decisions. }\end{array}$ & Negative affect: 2,7 , and 8 \\
\hline 5. Right now, I feel relaxed. & Positive affect: 1, 5 \\
\hline 6. Right now, I feel lonely. & $\begin{array}{l}\text { Positive appraisals about patients' } \\
\text { behaviors: } 31,32 \text {, and } 34\end{array}$ \\
\hline \multicolumn{2}{|l|}{ 7. Right now, I feel irritable. } \\
\hline \multicolumn{2}{|l|}{ 8. Right now, I feel anxious. } \\
\hline \multicolumn{2}{|l|}{ 9. Right now, I feel hopeful. } \\
\hline \multicolumn{2}{|l|}{ 10. Right now, I feel guilty. } \\
\hline \multicolumn{2}{|l|}{ 11. Right now, I have difficulty controlling } \\
\hline my thoughts and emotions. & \\
\hline \multicolumn{2}{|l|}{ 12. Right now, I like what I am doing. } \\
\hline \multicolumn{2}{|l|}{ 13. Right now, I feel tired. } \\
\hline \multicolumn{2}{|l|}{ 14. Right now, I don't feel physically well. } \\
\hline \multicolumn{2}{|l|}{ 15. Right now, I feel supported. } \\
\hline \multicolumn{2}{|l|}{ 16. My current situation is positive. } \\
\hline \multicolumn{2}{|l|}{ 17. My current situation is stressful. } \\
\hline \multicolumn{2}{|l|}{ 18. Right now, I feel happy with he/she. } \\
\hline \multicolumn{2}{|l|}{ 19. Right now, I am worried about he/she. } \\
\hline \multicolumn{2}{|l|}{ 20. Right now, I feel exhausted by he/she. } \\
\hline \multicolumn{2}{|l|}{$\begin{array}{l}\text { 21. Right now, I feel disappointed by he/ } \\
\text { she. }\end{array}$} \\
\hline \multicolumn{2}{|l|}{ 22. Right now, I am angry with he/she. } \\
\hline \multicolumn{2}{|l|}{ 23. Right now, I feel close to he/she. } \\
\hline \multicolumn{2}{|l|}{ 24. Right now, it is difficult to deal with } \\
\hline \multicolumn{2}{|l|}{ he/she. } \\
\hline \multicolumn{2}{|l|}{$\begin{array}{l}\text { 25. Right now, I feel that he/she doesn't } \\
\text { make an effort to be well. }\end{array}$} \\
\hline \multicolumn{2}{|l|}{ 26. Right now, he/she is a burden to me. } \\
\hline \multicolumn{2}{|l|}{ 27. Right now, I feel he/she cannot } \\
\hline \multicolumn{2}{|l|}{ 28. ¿Are you with he/she right now? [If } \\
\hline \multicolumn{2}{|l|}{ YES selected: Q31-Q36/If NO } \\
\hline selected: Q29] & \\
\hline 29. Since the last beep, did you have & \\
\hline contact with he/she? [If YES selected: & \\
\hline Q31-36/If NO selected: Q30 and END & \\
\hline of SURVEY] & \\
\hline 30. Right now, I wish he/she was here. & \\
\hline 31. Right now, he/she is functioning well. & \\
\hline 32. Right now, he/she is in a good mood. & \\
\hline 33. Right now, he/she is being disruptive. & \\
\hline 34. Right now, it is good to have he/she & \\
\hline around. & \\
\hline $\begin{array}{l}\text { 35. Right now, he/she makes me feel } \\
\text { exhausted. }\end{array}$ & \\
\hline 36. Right now, he/she is a burden to me. & \\
\hline
\end{tabular}

a standard approach for the analysis of ESM data $(67,68)$. Level 1 predictors were group-mean centered, level 2 predictors were grand-mean centered, and parameter estimates were calculated using robust standard errors. Two types of multilevel analyses were conducted in the present study. Firstly, a series of multilevel regressions were conducted to test the impact of momentary criticism and EOI (level 1 predictors) on emotional, cognitive, and interpersonal experiences in daily life. Secondly, multilevel regressions were performed to explore the impact of FQ-EE dimensions (level 2 predictors) on ESM domains in daily life (level 1 dependent measures).

\section{RESULTS}

\section{Associations Between Momentary Expressed Emotion and Family Questionnaire-Expressed Emotion Dimensions}

Momentary criticism and momentary EOI were significantly correlated in the present sample $(r=0.59, p=0.000$, LLCI $=0.425$, ULCI $=0.719)$. Pearson's correlations revealed strong associations between momentary criticism and FQ-criticism $(r=0.66, p=0.000$, $\mathrm{LLCI}=0.452$, ULCI $=0.814$ ), as well as between momentary EOI and FQ-EOI $(r=0.51, p=0.000, \mathrm{LLCI}=0.305, \mathrm{ULCI}=0.675)$. Following Cohen (65), effect sizes were of large magnitude. Significant associations were also found between momentary criticism and FQ-EOI $(\mathbf{r}=0.42, p=0.002$, LLCI $=0.175$, ULCI $=0.623)$ as well as between momentary EOI and FQ-criticism $(r=0.45, p=0.001$, LLCI $=0.242$, ULCI $=0.640)$, both medium effect sizes

\section{Associations Between Momentary Expressed Emotion and Emotional, Cognitive, and Interpersonal Experiences in Daily Life}

Table 2 presents the direct effects of the momentary EE dimensions on relatives' daily life experiences. As expected, momentary criticism and EOI were associated with increased NA and decreased PA in daily life. Additionally, both momentary EE dimensions were related with decreased appraisals of effective coping in everyday life.

In terms of appraisals about the current situation, momentary criticism and EOI were associated with a decreased enjoyment of current activities and perceiving the current situation as less positive. Momentary criticism was associated with reports that the current situation was stressful, whereas contrary to expectations, momentary EOI was not. In relation to burden, both momentary EE domains showed significant associations with increased appraisals of feeling burdened by the patient. Also, contrary to our hypotheses, no differential associations emerged for the momentary EE dimensions in relation to illness attributions. Both momentary EE dimensions were significantly associated with attributions of patients' control over the disorder as well as with attributions of relatives' personal control over the disorder in daily life.

Regarding negative and positive appraisals related to the self, momentary criticism was related to appraisals of feeling less supported, whereas momentary EOI was associated with feelings of being lonely. No associations were found between momentary $\mathrm{EE}$ and appraisals of hope and guilt. In relation to relatives' positive appraisals about the patient, momentary criticism, and EOI were associated with expressing decreased feelings of happiness in relation to the patient and less reports of feeling emotionally close to the patient.

As for relatives' appraisals in situations of direct and/or recent contact with the patient, momentary criticism and EOI were 
TABLE 2 | Direct effects of momentary expressed emotion dimensions on relatives' daily life experiences.

Level 1 predictors

\begin{tabular}{|c|c|c|c|c|c|c|c|c|}
\hline & \multirow[t]{2}{*}{ Momentary criticism } & \multirow[t]{2}{*}{$\boldsymbol{P}$} & \multicolumn{2}{|c|}{$95 \% \mathrm{Cl}$} & \multirow[t]{2}{*}{ Momentary EOI } & \multirow[t]{2}{*}{$P$} & \multicolumn{2}{|c|}{$95 \% \mathrm{Cl}$} \\
\hline & & & Lower & Upper & & & Lower & Upper \\
\hline \multicolumn{9}{|l|}{ Affect in the moment } \\
\hline Negative affect index & $0.440(\mathrm{SE}=0.103)$ & 0.000 & 0.238 & 0.642 & 0.092 (SE = 0.028) & 0.001 & 0.037 & 0.147 \\
\hline Positive affect index & $-0.399(\mathrm{SE}=0.081)$ & 0.000 & -0.558 & -0.267 & $-0.150(\mathrm{SE}=0.030)$ & 0.000 & -0.208 & -0.091 \\
\hline \multicolumn{9}{|l|}{ Appraisals of effective coping } \\
\hline Right now, I feel I can cope with things well. & $-0.173(\mathrm{SE}=0.056)$ & 0.002 & -0.284 & -0.063 & $-0.070(\mathrm{SE}=0.034)$ & 0.037 & -0.136 & -0.004 \\
\hline \multicolumn{9}{|l|}{ Appraisals about the current situation } \\
\hline My current situation is positive. & $-0.214(\mathrm{SE}=0.070)$ & 0.002 & -0.351 & -0.076 & $-0.073(\mathrm{SE}=0.030)$ & 0.013 & -0.131 & -0.015 \\
\hline Right now, I like what I am doing. & $-0.190(\mathrm{SE}=0.056)$ & 0.001 & -0.300 & -0.080 & $-0.057(\mathrm{SE}=0.028)$ & 0.044 & -0.112 & -0.001 \\
\hline My current situation is stressful. & $0.366(\mathrm{SE}=0.062)$ & 0.000 & 0.245 & 0.468 & $0.033(\mathrm{SE}=0.030)$ & 0.271 & -0.026 & 0.093 \\
\hline \multicolumn{9}{|l|}{ Appraisals of burden } \\
\hline Right now, he/she is a burden to me. & $0.321(\mathrm{SE}=0.097)$ & 0.001 & 0.131 & 0.512 & $0.112(\mathrm{SE}=0.039)$ & 0.004 & 0.036 & 0.188 \\
\hline \multicolumn{9}{|l|}{ Illness attributions } \\
\hline \multicolumn{9}{|l|}{ Attributions of patients' control over the disorder } \\
\hline $\begin{array}{l}\text { Right now, I feel that he/she doesn't make an } \\
\text { effort to be well. }\end{array}$ & $0.473(\mathrm{SE}=0.102)$ & 0.000 & 0.273 & 0.673 & $0.157(\mathrm{SE}=0.042)$ & 0.000 & 0.075 & 0.238 \\
\hline \multicolumn{9}{|l|}{ Attributions of relatives' control over the disorder } \\
\hline $\begin{array}{l}\text { Right now, I feel that he/she cannot function } \\
\text { without me. }\end{array}$ & $0.167(\mathrm{SE}=0.070)$ & 0.017 & 0.030 & 0.304 & $0.090(\mathrm{SE}=0.030)$ & 0.002 & 0.032 & 0.149 \\
\hline \multicolumn{9}{|l|}{ Appraisals related to the self } \\
\hline \multicolumn{9}{|l|}{ Positive appraisals } \\
\hline Right now, I feel hopeful. & $-0.077(\mathrm{SE}=0.050)$ & 0.120 & -0.175 & 0.020 & $-0.036(\mathrm{SE}=0.019)$ & 0.062 & -0.075 & 0.002 \\
\hline Right now, I feel supported. & $-0.157(\mathrm{SE}=0.063)$ & 0.013 & -0.281 & -0.034 & $-0.055(\mathrm{SE}=0.035)$ & 0.110 & -0.123 & 0.012 \\
\hline \multicolumn{9}{|l|}{ Negative appraisals } \\
\hline Right now, I feel lonely. & $0.211(\mathrm{SE}=0.151)$ & 0.160 & -0.084 & 0.507 & $0.063(\mathrm{SE}=0.028)$ & 0.026 & 0.008 & 0.118 \\
\hline Right now, I feel guilty. & $0.089(\mathrm{SE}=0.062)$ & 0.148 & -0.032 & 0.210 & $0.037(\mathrm{SE}=0.024)$ & 0.125 & -0.010 & 0.084 \\
\hline \multicolumn{9}{|l|}{ Positive appraisals about the patient } \\
\hline Right now, I feel happy with he/she. & $-0.605(\mathrm{SE}=0.128)$ & 0.000 & -0.856 & -0.354 & $-0.183(\mathrm{SE}=0.051)$ & 0.000 & -0.283 & -0.082 \\
\hline Right now, I feel close to he/she. & $-0.324(\mathrm{SE}=0.094)$ & 0.001 & -0.509 & -0.139 & $-0.056(\mathrm{SE}=0.026)$ & 0.031 & -0.107 & -0.005 \\
\hline \multicolumn{9}{|c|}{ Appraisals in situations of direct and/or recent contact with the patient } \\
\hline \multicolumn{9}{|l|}{ Negative appraisals about patients' behaviors } \\
\hline Right now, he/she is being disruptive. & $0.498(\mathrm{SE}=0.072)$ & 0.000 & 0.357 & 0.639 & $0.198(\mathrm{SE}=0.039)$ & 0.000 & 0.121 & 0.274 \\
\hline Right now, he/she makes me feel exhausted. & $0.462(\mathrm{SE}=0.082)$ & 0.000 & 0.301 & 0.623 & $0.116(\mathrm{SE}=0.048)$ & 0.017 & 0.021 & 0.211 \\
\hline Right now, he/she is a burden to me. & $0.264(\mathrm{SE}=0.154)$ & 0.085 & -0.037 & 0.566 & $0.044(\mathrm{SE}=0.053)$ & 0.407 & -0.060 & 0.148 \\
\hline $\begin{array}{l}\text { Positive appraisals about patients' } \\
\text { behaviors index }\end{array}$ & $-0.359(\mathrm{SE}=0.052)$ & 0.000 & -0.461 & -0.257 & $-0.181(\mathrm{SE}=0.036)$ & 0.000 & -0.251 & -0.112 \\
\hline
\end{tabular}

EE,expressed emotion; EOI,emotional over-involvement; SE, standard error; 95\% Cl,95\% confidence interval.

associated with current appraisals of feeling exhausted by the patient as well as with perceiving the current patient's behavior as disruptive. There were no associations between momentary EE and appraisals of burden. Moreover, both momentary EE dimensions were inversely related to positive appraisals about patients' behaviors when relatives were interacting and/or had recently interacted with the patient.

\section{Impact of Psychometric Expressed Emotion Dimensions on Emotional, Cognitive, and Interpersonal Experiences in Daily Life}

FQ criticism and EOI scores were significantly correlated in the present sample $(r=0.72, p=0.000, \mathrm{LLCI}=0.576$, ULCI $=$ $0.823)$. Table 3 presents the direct effects of FQ-EE dimensions on relatives' daily life experiences. FQ-criticism was related with the momentary criticism index and its four individual items. Specifically, FQ-criticism was associated with increased reports of feeling exhausted by the patient, disappointed and angry with the patient, as well as with an increased perception of difficulties for dealing with the patient. FQ-criticism was also related to momentary EOI. On the other hand, FQ-EOI was related to momentary EOI that is, to increased reports of worry about the patient. In addition, FQ-EOI was associated with the momentary criticism index, specifically with feeling exhausted by the patient and perceiving difficulties in dealing with the patient, but not with feeling disappointed or angry with the patient.

Although none of two FQ-EE dimensions showed significant relationships with momentary NA, both were inversely related to momentary PA. Furthermore, both dimensions were related to decreased appraisals of effective coping in daily life.

In terms of situational appraisals, both dimensions were associated with perceiving situations as less positive and more 
TABLE 3 | Direct effects of psychometric expressed emotion dimensions on relatives' daily life experiences.

Level 2 predictors

\begin{tabular}{|c|c|c|c|c|c|c|c|c|}
\hline & \multirow[t]{2}{*}{ FQ-criticism } & \multirow[t]{2}{*}{$P$} & \multicolumn{2}{|c|}{$95 \% \mathrm{Cl}$} & \multirow[t]{2}{*}{ FQ-EOI } & \multirow[t]{2}{*}{$\boldsymbol{P}$} & \multicolumn{2}{|c|}{$95 \% \mathrm{Cl}$} \\
\hline & & & Lower & Upper & & & Lower & Upper \\
\hline \multicolumn{9}{|l|}{ Momentary EE } \\
\hline Momentary criticism-index & $0.091(\mathrm{SE}=0.014)$ & 0.000 & 0.064 & 0.118 & $0.062(\mathrm{SE}=0.018)$ & 0.001 & 0.026 & 0.097 \\
\hline Right now, I feel exhausted by he/she. & $0.091(\mathrm{SE}=0.018)$ & 0.000 & 0.056 & 0.126 & $0.093(\mathrm{SE}=0.018)$ & 0.000 & 0.057 & 0.129 \\
\hline Right now, I feel disappointed by he/she. & $0.081(\mathrm{SE}=0.021)$ & 0.000 & 0.039 & 0.122 & $0.045(\mathrm{SE}=0.024)$ & 0.065 & -0.003 & 0.093 \\
\hline Right now, I am angry with he/she. & $0.048(\mathrm{SE}=0.014)$ & 0.001 & 0.020 & 0.076 & $0.022(\mathrm{SE}=0.018)$ & 0.226 & -0.013 & 0.057 \\
\hline Right now, it is difficult to deal with he/she. & $0.144(\mathrm{SE}=0.021)$ & 0.000 & 0.103 & 0.186 & $0.088(\mathrm{SE}=0.032)$ & 0.006 & 0.626 & 1.166 \\
\hline Momentary EOI & $0.117(\mathrm{SE}=0.028)$ & 0.000 & 0.062 & 0.172 & $0.141(\mathrm{SE}=0.028)$ & 0.000 & 0.086 & 0.197 \\
\hline \multicolumn{9}{|l|}{ Affect in the moment } \\
\hline Negative affect-index & $0.043(\mathrm{SE}=0.025)$ & 0.079 & -0.005 & 0.092 & $0.045(\mathrm{SE}=0.025)$ & 0.076 & -0.005 & 0.094 \\
\hline Positive affect-index & $-0.065(\mathrm{SE}=0.024)$ & 0.007 & -0.112 & -0.018 & $-0.074(\mathrm{SE}=0.025)$ & 0.003 & -0.114 & 0.025 \\
\hline \multicolumn{9}{|l|}{ Appraisals of effective coping } \\
\hline Right now, I feel I can cope with things well. & $-0.075(\mathrm{SE}=0.017)$ & 0.000 & -0.108 & -0.043 & $-0.070(\mathrm{SE}=0.018)$ & 0.000 & -0.105 & -0.035 \\
\hline \multicolumn{9}{|l|}{ Appraisals about the current situation } \\
\hline My current situation is positive. & $-0.071(\mathrm{SE}=0.019)$ & 0.000 & -0.108 & -0.034 & $-0.083(\mathrm{SE}=0.022)$ & 0.000 & -0.125 & -0.040 \\
\hline Right now, I like what I am doing. & $-0.032(\mathrm{SE}=0.020)$ & 0.104 & -0.070 & 0.007 & $-0.038(\mathrm{SE}=0.020)$ & 0.060 & -0.078 & 0.002 \\
\hline My current situation is stressful. & $0.082(\mathrm{SE}=0.023)$ & 0.000 & 0.037 & 0.128 & $0.065(\mathrm{SE}=0.030)$ & 0.031 & 0.006 & 0.124 \\
\hline \multicolumn{9}{|l|}{ Appraisals of burden } \\
\hline Right now, he/she is a burden to me. & $0.117(\mathrm{SE}=0.048)$ & 0.015 & 0.023 & 0.211 & $0.090(\mathrm{SE}=0.048)$ & 0.058 & -0.003 & 0.012 \\
\hline \multicolumn{9}{|l|}{ Illness attributions } \\
\hline \multicolumn{9}{|l|}{ Attributions of patients' control over the disorder } \\
\hline $\begin{array}{l}\text { Right now, I feel that he/she doesn't make an effort } \\
\text { to be well. }\end{array}$ & $0.091(\mathrm{SE}=0.024)$ & 0.000 & 0.044 & 0.138 & $0.054(\mathrm{SE}=0.028)$ & 0.050 & 0.000 & 0.108 \\
\hline \multicolumn{9}{|l|}{ Attributions of relatives' control over the disorder } \\
\hline $\begin{array}{l}\text { Right now, I feel that he/she cannot function without } \\
\text { me. }\end{array}$ & $0.134(\mathrm{SE}=0.032)$ & 0.000 & 0.070 & 0.198 & $0.135(\mathrm{SE}=0.032)$ & 0.000 & 0.072 & 0.198 \\
\hline \multicolumn{9}{|l|}{ Appraisals related to the self } \\
\hline \multicolumn{9}{|l|}{ Positive appraisals } \\
\hline Right now, I feel hopeful. & $-0.041(\mathrm{SE}=0.017)$ & 0.017 & -0.074 & -0.007 & $-0.046(\mathrm{SE}=0.019)$ & 0.016 & -0.083 & -0.008 \\
\hline Right now, I feel supported. & $-0.049(\mathrm{SE}=0.030)$ & 0.099 & -0.106 & 0.009 & $-0.048(\mathrm{SE}=0.027)$ & 0.074 & -0.101 & 0.005 \\
\hline \multicolumn{9}{|l|}{ Negative appraisals } \\
\hline Right now, I feel lonely. & 0.053 (SE = 0.032) & 0.093 & -0.009 & 0.115 & $0.047(\mathrm{SE}=0.030)$ & 0.115 & -0.011 & 0.104 \\
\hline Right now, I feel guilty. & $0.089(\mathrm{SE}=0.042)$ & 0.034 & 0.007 & 0.171 & $0.106(\mathrm{SE}=0.040)$ & 0.008 & 0.027 & 0.184 \\
\hline \multicolumn{9}{|l|}{ Positive appraisals about the patient } \\
\hline Right now, I feel happy with he/she. & $-0.083(\mathrm{SE}=0.026)$ & 0.001 & -0.134 & -0.033 & $-0.099(\mathrm{SE}=0.028)$ & 0.000 & -0.154 & -0.044 \\
\hline Right now, I feel close to he/she. & $-0.065(\mathrm{SE}=0.027)$ & 0.016 & -0.117 & -0.012 & $-0.044(\mathrm{SE}=0.027)$ & 0.100 & -0.097 & 0.009 \\
\hline \multicolumn{9}{|c|}{ Appraisals in situations of direct and/or recent contact with the patient } \\
\hline \multicolumn{9}{|c|}{ Negative appraisals about patients' behaviors } \\
\hline Right now, he/she is being disruptive. & $0.117(\mathrm{SE}=0.022)$ & 0.000 & 0.074 & 0.160 & $0.072(\mathrm{SE}=0.028)$ & 0.010 & 0.017 & 0.128 \\
\hline Right now, he/she makes me feel exhausted. & $0.088(\mathrm{SE}=0.025)$ & 0.000 & 0.039 & 0.136 & $0.083(\mathrm{SE}=0.025)$ & 0.001 & 0.035 & 0.132 \\
\hline Right now, he/she is a burden to me. & $0.012(\mathrm{SE}=0.041)$ & 0.764 & -0.068 & 0.093 & $-0.032(\mathrm{SE}=0.048)$ & 0.513 & -0.126 & 0.063 \\
\hline Positive appraisals about patients' behaviors index & $-0.066(\mathrm{SE}=0.017)$ & 0.000 & -0.099 & -0.033 & $-0.054(\mathrm{SE}=0.018)$ & 0.002 & -0.090 & -0.019 \\
\hline
\end{tabular}

FQ, Family Questionnaire; EE, expressed emotion; EOI, emotional over-involvement; SE, standard error; 95\% CI,95\% confidence interval.

stressful. No associations were found with appraisals of enjoyment of current activities. Unlike FQ-EOI, FQ-criticism was associated with increased momentary reports of feeling burdened by the patient. Regarding illness attributions, both dimensions were associated with attributions of relatives' personal control over the disorder. However, only FQ-criticism was associated with increased attributions of patients' control over the disorder as expected.

As for negative and positive appraisals related to the self, both dimensions were associated with guilt and diminished hopefulness, but were unassociated with feeling supported or lonely. Both dimensions were associated with decreased feelings of happiness with the patient. However, only FQ-criticism was associated with feeling less close to the patient.
No differential associations were found in relation to the appraisals in situations of direct and/or recent contact with the patient. Both FQ-criticism and FQ-EOI displayed significant relationships with increased reports of feeling exhausted by the patient as well as with perceiving the patient's behavior as disruptive. No associations were found between EE and burden. Moreover, both FQ dimensions were inversely related to positive appraisals about patients' behaviors.

\section{DISCUSSION}

To the best of our knowledge, this is the first study to explore how EE dimensions, as measured by momentary and psychometric 
self-reports, are expressed in daily life by using ESM in a sample of caregivers of patients with early psychosis. Consistent with our hypotheses, momentary criticism and FQ-criticism, as well as momentary EOI and FQ-EOI, displayed significant associations of a large magnitude, thus providing support for the criterion validity of momentary EE dimensions. Furthermore, findings showed that both momentary EE and FQ-EE dimensions were significantly and meaningfully associated with real-world experiences pertaining to psychological domains that have been previously related to EE in retrospective and psychometric studies that are critical to the definition of EE from a theoretical standpoint. Overall, the findings partly support the construct validity of momentary criticism and EOI as well as the construct and ecological validity of the FQ.

The strong association between analogous EE momentary and psychometric dimensions supported the criterion validity of momentary criticism and EOI assessments. However, there were also significant associations between momentary criticism and FQ-EOI, as well as between momentary EOI and FQ-criticism-although of a medium, not large, magnitude. Hence, momentary criticism and momentary EOI appear to be relatively non-specific indicators of each respective $\mathrm{EE}$ dimension (i.e., criticism and EOI). A detailed examination of the relationship between FQ-EOI and the four individual items comprised in the momentary criticism index partially supported the discriminant validity of the FQ-EOI dimension, as FQ-EOI was associated to feeling exhausted by the patient and perceiving difficulties for dealing with the patient, but not with the most representative appraisals of the momentary criticism index (i.e., feeling disappointed and angry with the patient). Overall, our findings concur with previous research indicating significant associations between the EE dimensions $(69,70)$ which contrasts with previous suggestions posing that they are uncorrelated and represent independent constructs (44-46).

Overall, the results regarding the daily life expression of criticism and EOI dimensions partly confirmed our hypotheses. Momentary criticism and EOI were related to increased NA and decreased PA, consistent with previous work indicating that early psychosis relatives often report high levels anxiety and depression associated to high levels of $\mathrm{EE}(20,24,26,27)$. However, FQ-EE dimensions were only associated to decreased PA in daily life, suggesting that momentary measure of $\mathrm{EE}$ is more sensitive for capturing NA experiences. Furthermore, both momentary and psychometric EE indicators were related to appraisals of less effective coping in daily life. This finding is in accordance with previous results from the schizophrenia literature showing that relatives with high-EE perceive their coping ability as poorer than those with low-EE (38), and further supports the assumption that EE could be deemed as a maladaptive coping strategy used in an attempt to reduce the perceived stress related to the caregiving role $(25,37)$.

Regarding relatives' appraisals about the situation, results showed that FQ and momentary criticism and EOI were associated with reports that the current situation was less positive. However, unlike FQ-EE dimensions, momentary EE dimensions also displayed associations with expressing decreased enjoyment regarding current activities. Consistent with our results,
Hooley and Hiller (71) found that relatives of schizophrenia patients with high-EE reported reduced satisfaction about their individual activities compared to low-EE relatives. It is likely that the momentary nature of ESM allows to capture with higher sensitivity the rewarding capacity of situations encountered in the flow of daily life compared to retrospective inventories.

In line with our hypotheses, momentary criticism and FQ-criticism were related to daily appraisals of situational stress and burden. However, momentary EOI and FQ-EOI showed discrepancies in their association to burden and stress. FQ-EOI, but not momentary EOI, was associated with increased appraisals of situational stress, whereas only momentary EOI was related with increased appraisals of feeling burdened by the patient. Thus, criticism had a clearer association with situational stress and burden than EOI. Overall, these results seem to be partially consistent with previous early psychosis findings indicating an association of EE with relatives' distress and/or burden (20, $22,24)$ but do not replicate previous early psychosis research suggesting that EOI is more strongly related to distress and burden than criticism $(17,25-27)$.

Partly in contrast with our hypotheses, a distinct pattern of associations was not observed for momentary and FQ-EE dimensions in relation to illness attributions. As expected, momentary criticism and FQ-criticism were associated with increased attributions of patients' control over the disorder. This result agrees with previous findings in early psychosis (30, 31) and is consistent with the attributional model of EE (29). However, momentary EOI was also associated with attributions of control over the disorder by the patient. This seems to be partly incongruent with the attributional model of EE referred above, which posits a specific relationship between criticism and attributions regarding patients' ability to control their behaviors. Notwithstanding, EOI has also been related with attributions of control by the patient in the early stages of psychosis (20). On the other hand, and in line with previous studies relating EOI with relatives' self-control attributions (34), both momentary EOI and FQ-EOI were related to attributions of relatives' control over the disorder. However, in contrast with our hypotheses, both momentary criticism and FQ-criticism were also related to selfcontrol attributions. It is attractive to speculate that at the early stages of the disorder, when there is great confusion and still a low level of knowledge about the disorder, a great majority of relatives still exhibit low-defined illness attributions. Thus, relatives may believe that they can control the disorder by themselves and, at the same time, that patients can have a significant control over their behavior, which may explain the finding of a lack of differential patterns between illness attributions and EE attitudes. As the disorder progresses, relatives may entrench more defined illness attributions which, in turn, delineate more specific behavioral reactions. Moreover, it is likely that the high-emotional impact of early psychosis on caregivers leads them to a low understanding of their own feelings (i.e., diminished emotional clarity). Presumably, low levels of emotional clarity may affect the way they appraise patients' behaviors thus provoking relatives' cognitive ambivalence regarding the control of the disorder. Thus, the attributional model of EE based on schizophrenia samples should be tailored to the developmental specificities of early 
psychosis (20). This would require integrating the pivotal role of emotional factors influencing the psychological experience of relatives in at-risk and onset stages of the disorder.

Regarding positive and negative appraisals related to the self, our results showed that, unlike momentary EE, both FQ-EE dimensions were associated with increased reports of feeling guilt in daily life. Previous studies have reported associations between relatives' guilt related to the patient's illness and EOI behaviors $(35,36)$. However, Wasserman et al. (72) also found relatives' guilt/self-blame to be associated with high-EE overall status and posited that relatives may defend against the experience of blaming themselves by putting the blame onto the patient in a critical manner or by behaving in an emotionally over-involved way to repair their wrongdoing. Furthermore, unlike momentary EE, both FQ-EE dimensions were associated to decreased reports of hopefulness. Hopefulness has not been studied in relation to $\mathrm{EE}$, although it has been conceived as crucial in the process of coping with a psychiatric disorder in a close family member (73, 74). Finally, only momentary criticism was related to appraisals of feeling less supported, whereas momentary EOI was associated with feelings of being lonely. In essence, these appraisals could be conceived as indicators of perceived social support. Of note, recent research has found $\mathrm{EE}$ to be related with a decreased perception of social support in schizophrenia relatives (75).

In regard to the association of criticism and EOI with daily positive appraisals about the ill relative, both momentary and FQ-EE dimensions were related to decreased happiness regarding their relative. Also, both momentary EE domains and FQ-criticism (but not FQ-EOI) were associated with reports of feeling less close to the patient. Given that EOI is characterized by the expression of extreme emotional closeness with the patient (i.e., overidentification) (76), it is not surprising that FQ-EOI was not related to decreased feelings of closeness. The relationship between momentary EOI and appraisals of decreased closeness might indicate that our measure of EOI, based on the core element of "worrying" but restricted to it, has not been sufficient to capture all the nuances of this construct and/or that the number of daily-life assessments was not extensive enough to capture sufficient variance in such sensitive assessment regarding the parental bond.

As for relatives' appraisals about the ill relative when relatives were in direct contact and/or had had recent contact with the patient, both momentary and FQ-EE dimensions were related with decreased positive appraisals about patients' behaviors as well as with increased reports of feeling exhausted by the patient and/or with perceiving the patient's behavior as disruptive in the current situation. This is consistent with findings that relatives of schizophrenia patients holding highly critical or emotionally overinvolved attitudes tend to show lower levels of accepting behavior (77) and make more negative statements (e.g., criticism, statements of disagreement) during face-to-face interactions with patients than do low-EE relatives $(42,43,78)$. Also, our results concur with previous studies indicating that criticism is related to "belittling and blaming" statements (53) and/or with statements of disgust and harshness in parent-patient interactions (50). However, contrary to our findings, some researchers have found EOI associated with high rates of positive/supportive statements in interaction studies (54).
Regarding relatives' appraisals of burden in situations of direct and/or recent contact with the patient, an interesting finding emerged thanks to the use of ESM. The item assessing burden was prompted at all assessment points (i.e., independent of whether relatives were with the patient) and also appeared at the end of the questionnaire within the interactional items (i.e., those that relatives only answered if they had direct or recent contact with the patient since the last beep). Of note, both momentary EE dimensions and FQ-criticism, but not FQ-EOI, showed associations with burden when this item was asked in the general part of the questionnaire. However, when answering the same item when in direct or recent contact with the patient, relatives reported negative appraisals as mentioned (being disruptive, makes me feel exhausted), but not feeling burdened. An important difference of this item and the other negative appraisals is that burden is a direct negative assessment of the person, not of behaviors, which may explain the difference in the pattern of responses. This finding underscores the relevance of assessing contextual factors to capture the contextual variability of psychological phenomena.

The following limitations should be acknowledged when interpreting the results. First, our ESM measure of EOI [ESM item: 'I am worried about (the patient)'] was necessarily brief and concentrated on an essential element but is likely too narrow. Although EOI is characterized by relatives' over-concern, it is also defined by excessive self-sacrifice, over-identification, and extreme over-protective behavior with the patient (76). Thus, our momentary EOI measure was probably not comprehensive enough to capture the full range of EOI attitudes. Second, it should be noted that we have examined the impact of momentary EE dimensions on momentary emotional and cognitive correlates to investigate the daily life expression of criticism and EOI; nevertheless, given the correlational nature of these data, the opposite interpretation is also plausible (e.g., increased NA contributing to increased reports of momentary EE). Future research should examine whether specific patterns of momentary emotional and cognitive experiences predict the emergence of momentary EE at subsequent assessments using longitudinal designs. Finally, it must be pointed out that the sample size of the present study $(n=55)$ might be considered relatively small given the number of analyses conducted. However, it must be taken into consideration that it is a substantial sample size in the context of this specific literature. Furthermore, the present study has a sufficient within-person sample based upon the total number of ESM observations. Hox (79) advocates the "50/20 rule" for assessing multilevel data, suggesting that studies should have a minimum of 20 measurements nested within a minimum of 50 participants, which indicates that our study should be adequately powered to test our ESM hypotheses.

The expression of EE dimensions in real time as relatives navigate their real-life settings remains a largely unexplored area of research. This study provided a novel contribution by using momentary as well as psychometric measures to examine the expression of relatives' $\mathrm{EE}$ in relation to a wide variety of realworld experiences. Although criticism and EOI, as measured by momentary and psychometric self-reports, were expected to show relatively differential relationships with daily-life appraisals 
and caregivers' subjective states in real-world settings, this study only partly supports the construct validity of momentary EE assessments and the construct and ecological validity of the FQ dimensions. This "low-specificity" pattern of relationships between criticism and EOI with real-world experiences might be related to a developmental issue. The fact that the patients are at an early risk or onset stage of the illness process may indicate that their relatives hyperactivate both the caregiving behavioral system to overprotect the patients, as well as coercive and critical attitudes as an attempt to restore the lost normal behavior and healthy person; these would, respectively, raise EOI and criticism attitudes. It is possible that if the illness progresses and becomes chronic, relatives may start to display a stronger tendency toward either criticism or EOI depending on a complex number of factors pertaining to both the relative (e.g., illness attributions, attachment style) and the patient (e.g., severity, disability).

The present study highlights the utility of ESM for assessing how the predictions derived from EE theory play out in the natural family environment. From a clinical viewpoint, the use of ESM provides a detailed assessment of emotional, cognitive, and behavioral EE components and allows for the critical study of contextual influences such as the caregiver-patient interaction. This enhanced comprehension of the expression of EE in the flow of daily life should facilitate the adaptation of models of EE derived from chronic forms of the disorder to the specificities of early psychosis as well as the development of targeted and personalized interventions, including novel approaches such as ecological momentary interventions (e.g., 80).

\section{DATA AVAILABILITY STATEMENT}

The datasets generated for this study are available on request to the corresponding author.

\section{ETHICS STATEMENT}

The studies involving human participants were reviewed and approved by Ethics Committee of the Unió Catalana d'Hospitals

\section{REFERENCES}

1. Fusar-Poli P, Borgwardt S, Bechdolf A, Addington J, Riecher-Rössler A, Schultze-Lutter F, et al. The psychosis high-risk state: a comprehensive stateof-the-art review. Arch Gen Psychiatry (2013) 701:107-20. doi: 10.1001/ jamapsychiatry.2013.269

2. McGorry P. Preventive strategies in early psychosis: verging on reality. $\mathrm{Br} \mathrm{J}$ Psychiatry (1998) 172:1-2. doi: 10.1192/S0007125000297572

3. Morrison AP, Stewart SLK, French P, Bentall RP, Birchwood M, Byrne R, et al. Early detection and intervention evaluation for people at high-risk of psychosis-2 (EDIE-2): Trial rationale, design and baseline characteristics. Early Interv. Psychiatry (2011) 5:24-32. doi: 10.1111/j.1751-7893.2010.00254.x

4. Bentall RP, Fernyhough C. Social predictors of psychotic experiences: Specificity and psychological mechanisms. Schizophr Bull (2008) 34:101220. doi: 10.1093/schbul/sbn103

5. Brown AS. The environment and susceptibility to schizophrenia. Prog Neurobiol (2011) 93:23-58. doi: 10.1016/j.pneurobio.2010.09.003
(Comitè d'Ètica d'Investigació Clínica (CEIC); number 09-40) and by the Ethics Committee of the Universitat Autònoma de Barcelona (Comissió d'Ėtica en l'Experimentació Animal i Humana (CEEAH); number 2679). The participants provided their written informed consent to participate in this study.

\section{AUTHOR CONTRIBUTIONS}

LH-M contributed to study conception, study design, data collection, data analyses, and writing of the manuscript. TD-M contributed to study conception, study design, data collection and critically revised the manuscript. TK contributed to study conception, study design, provided assistance regarding data analyses and critically revised the manuscript. NB-V was the principal investigator, conceived the study and contributed to study design and writing of the manuscript. All authors have read and approved the final manuscript.

\section{FUNDING}

This work is supported by the Spanish Ministerio de Economía y Competitividad (PSI2017-87512-C2-01) and the Comissionat per a Universitats i Recerca of Generalitat de Catalunya (2017SGR1612). $\mathrm{NB}-\mathrm{V}$ is supported by the Institució Catalana de Recerca i Estudis Avançats (ICREA) Academia Award and the Centro de Investigación Biomédica en Red de Salud Mental (CIBERSAM), Instituto de Salud Carlos III, Barcelona, Spain.

\section{ACKNOWLEDGMENTS}

The authors appreciate the support offered by the Fundació Sanitària Sant PereClaver and thank the families who participated in the study. We acknowledge Cristina MedinaPradas and Nieves Guardia for their contribution in the data collection. This paper is based on work appearing in a doctoral thesis (81).

6. Read J, Fosse R, Moskowitz A, Perry B. The traumagenic neurodevelopmental model of psychosis revisited. Neuropsychiatry (2014) 4:65-79. doi: 10.2217/ npy.13.89

7. Varese F, Smeets F, Drukker M, Lieverse R, Lataster T, Viechtbauer W, et al. Childhood adversities increase the risk of psychosis: A meta-analysis of patient-control, prospective-and cross-sectional cohort studies. Schizophr Bull (2012) 38:661-71. doi: 10.1093/schbul/sbs050

8. Brown GW, Birley JLT, Wing JK. Influence of family life on the course of schizophrenic disorders: a replication. Br J Psychiatry (1972) 121:241-58. doi: 10.1192/bjp.121.3.241

9. Butzlaff R, Hooley J. Expressed emotion and psychiatric relapse: a metaanalysis. Arch Gen Psychiatry (1998) 55:547- 52. doi: 10.1001/archpsyc.55.6.547

10. Cechnicki A, Bielańska A, Hanuszkiewicz I, Daren A. The predictive validity of Expressed Emotions (EE) in schizophrenia. A 20-year prospective study. J Psychiatr Res (2013) 47:208-14. doi: 10.1016/j.jpsychires.2012.10.004

11. Marom S, Munitz H, Jones PB, Weizman A, Hermesh H. Expressed emotion: Relevance to rehospitalization in schizophrenia over 7 years. Schizophr Bull (2005) 31:751-8. doi: 10.1093/schbul/sbi016 
12. Hooley JM. Expressed emotion and relapse of psychopathology. Annu Rev Clin Psychol (2007) 3:329-52. doi: 10.1146/annurev.clinpsy.2.022305.095236

13. Kavanagh DJ. Recent developments in expressed emotion and schizophrenia. Br J Psychiatry (1992) 160:601-20. doi: 10.1192/bjp.160.5.601

14. Koutra K, Vgontzas AN, Lionis C, Triliva S. Family functioning in firstepisode psychosis: a systematic review of the literature. Soc Psychiatry Psychiatr Epidemiol (2014) 49:1023-36. doi: 10.1007/s00127-013-0816-6

15. Meneghelli A, Alpi A, Pafumi N, Patelli G, Preti A, Cocchi A. Expressed emotion in first-episode schizophrenia and in ultra high-risk patients: results from the Programma2000 (Milan, Italy). Psychiatry Res (2011) 189:331-8. doi: 10.1016/j.psychres.2011.03.021

16. Bachmann S, Bottmer C, Jacob S, Kronmüller KT, Backenstrass M, Mundt C, et al. Expressed emotion in relatives of first-episode and chronic patients with schizophrenia and major depressive disorder-a comparison. Psychiatry Res (2002) 112:239-50. doi: 10.1016/S0165-1781(02)00226-3

17. González-Blanch C, Martín-Muñoz V, Pardo-García G, Martínez-García O, Álvarez-Jiménez M, Rodríguez-Sánchez JM, et al. Effects of family psychoeducation on expressed emotion and burden of care in first-episode psychosis: a prospective observational study. Span J Psychol (2010) 13:389-95. doi: $10.1017 / \mathrm{s} 1138741600003942$

18. O’Brien MP, Gordon JL, Bearden CE, Lopez SR, Kopelowicz A, Cannon TD. Positive family environment predicts improvement in symptoms and social functioning among adolescents at imminent risk for onset of psychosis. Schizophr Res (2006) 81:269-75. doi: 10.1016/j.schres.2005.10.005

19. Schlosser DA, Zinberg JL, Loewy RL, Casey-Cannon S, O’Brien MP, Bearden CE, et al. Predicting the longitudinal effects of the family environment on prodromal symptoms and functioning in patients at-risk for psychosis. Schizophr Res (2010) 118:69-75. doi: 10.1016/j.schres.2010.01.017

20. Domínguez-Martínez T, Medina-Pradas C, Kwapil TR, Barrantes-Vidal N. Relatives' expressed emotion, distress and attributions in clinical highrisk and recent onset of psychosis. Psychiatry Res (2017) 247:323-9. doi: 10.1016/j.psychres.2016.11.048

21. Möller-Leimkühler AM. Burden of relatives and predictors of burden. Baseline results from the Munich 5-year-follow-up study on relatives of first hospitalized patients with schizophrenia or depression. Eur Arch Psychiatry Clin Neurosci (2005) 255:223-31. doi: 10.1007/s00406-004-0550-x

22. Raune D, Kuipers E, Bebbington PE. Expressed emotion at first-episode psychosis: investigating a carer appraisal model. Br J Psychiatry (2004) 184:321-6. doi: 10.1192/bjp.184.4.321

23. Sadath A, Muralidhar D, Varambally S, Gangadhar BN, Jose JP. Do stress and support matter for caring? The role of perceived stress and social support on expressed emotion of carers of persons with first episode psychosis. Asian J Psychiatr (2017) 25:163-8. doi: 10.1016/j.ajp.2016.10.023

24. Tomlinson E, Onwumere J, Kuipers E. Distress and negative experiences of the caregiving relationship in early psychosis: Does social cognition play a role? Early Interv. Psychiatry (2014) 8:253-60. doi: 10.1111/eip.12040

25. Álvarez-Jiménez M, Gleeson JF, Cotton SM, Wade D, Crisp K, Yap MBH, et al. Differential predictors of critical comments and emotional overinvolvement in first-episode psychosis. Psychol. Med. (2010) 40:63-72. doi: $10.1017 /$ S0033291708004765

26. Jansen JE, Gleeson J, Cotton S. Towards a better understanding of caregiver distress in early psychosis: A systematic review of the psychological factors involved. Clin Psychol Rev (2015) 35:59-66. doi: 10.1016/j.cpr.2014.12.002

27. Jansen JE, Haahr UH, Harder S, Trauelsen AM, Lyse HG, Pedersen MB, et al. Caregiver distress in first-episode psychosis: the role of subjective appraisal, over-involvement and symptomatology. Soc Psychiatry Psychiatr Epidemiol (2015) 50:371-8. doi: 10.1007/s00127-014-0935-8

28. Jansen JE, Lysaker PH, Harder S, Haahr UH, Lyse HG, Pedersen MB, et al. Positive and negative caregiver experiences in first-episode psychosis: Emotional overinvolvement, wellbeing and metacognition. Psychol Psychother Theory Res Pract (2014) 87:298-310. doi: 10.1111/papt.12014

29. Barrowclough C, Hooley JM. Attributions and expressed emotion: a review. Clin Psychol Rev (2003) 23:849-80. doi: 10.1016/S0272-7358(03)00075-8

30. McNab C, Haslam N, Burnett P. Expressed emotion, attributions, utility beliefs, and distress in parents of young people with first episode psychosis. Psychiatry Res (2007) 151:97-106. doi: 10.1016/j.psychres.2006.08.004

31. Vasconcelos E Sa D, Wearden A, Barrowclough C. Expressed emotion, types of behavioural control and controllability attributions in relatives of people with recent-onset psychosis. Soc Psychiatry Psychiatr Epidemiol (2013) 48:1377-88. doi: 10.1007/s00127-013-0659-1

32. Barrowclough C, Johnston M, Tarrier N. Attributions, expressed emotion, and patient relapse: An attributional model of relatives' response to schizophrenic illness. Behav Ther (1994) 25:67-88. doi: 10.1007/s00127-013-0659-1

33. Brewin CR, MacCarthy B, Duda K, Vaughn CE, Abramson B. Attribution and expressed emotion in the relatives of patients with schizophrenia. J Abnorm Psychol (1991) 100:546-54. doi: 10.1037/0021-843X.100.4.546

34. Bolton C, Calam R, Barrowclough C, Peters S, Roberts J, Wearden A, et al. Expressed emotion, attributions and depression in mothers of children with problem behaviour. J Child Psychol Psychiatry (2003) 44:242-54. doi: 10.1111/1469-7610.00117

35. Bentsen H, Notland TH, Munkvold O-G, Boye B, Ulstein I, Bjorge H, et al. Guilt proneness and expressed emotion in relatives of patients with schizophrenia or related psychoses. Br J Med Psychol (1998) 71:125-38. doi: 10.1111/j.2044-8341.1998.tb01374.x

36. Peterson EC, Docherty NM. Expressed emotion, attribution, and control in parents of schizophrenic patients. Psychiatry (2004) 67:197-207. doi: 10.1521/psyc.67.2.197.35959

37. Kuipers E, Bebbington P, Dunn G, Fowler D, Freeman D, Watson P, et al. Influence of carer expressed emotion and affect on relapse in non-affective psychosis. Br J Psychiatry (2006) 188:173-9. doi: 10.1192/bjp.bp.104.007294

38. Smith J, Birchwood M, Cochrane R, George S. The needs of high and low expressed emotion families: a normative approach. Soc Psychiatry Psychiatr Epidemiol (1993) 28:11-6. doi: 10.1007/BF00797827

39. Hooley JM, Gotlib IH. A diathesis-stress conceptualization of expressed emotion and clinical outcome. Appl Prev Psychol (2000) 9:135-51. doi: 10.1016/S0962-1849(05)80001-0

40. Miklowitz DJ. The role of family systems in severe and recurrent psychiatric disorders: A developmental psychopathology view. Dev Psychopathol (2004) 16:667-88. doi: 10.1017/S0954579404004729

41. Miklowitz DJ, Goldstein MJ, Doane JA, Nuerchterlein KH, Strachan AM, Snyder KS, et al. Is expressed emotion an index of a transactional process? I. parents' affective style. Fam. Process (1989) 28:153-67. doi: 10.1111/j.15455300.1989.00153.x

42. Miklowitz DJ, Goldstein MJ, Falloon IRH, Doane JA. Interactional correlates of expressed emotion in the families of schizophrenics. Br J Psychiatry (1984) 144:482-7. doi: 10.1192/bjp.144.5.482

43. Valone K, Norton JP, Goldstein MJ, Doane JA. Parental expressed emotion and psychophysiological reactivity in an adolescent sample at risk for schizophrenia spectrum disorders. J Abnorm Psychol (1983) 92:399-407. doi: 10.1037//0021-843x.93.4.448

44. Chambless DL, Steketee G, Bryan AD, Aiken LS, Hooley JM. The structure of expressed emotion: A three-construct representation. Psychol Assess (1999) 11:67-76. doi: 10.1037/1040-3590.11.1.67

45. Scazufca M, Kuipers E. Stability of expressed emotion in relatives of those with schizophrenia and its relationship with burden of care and perception of patients' social functioning. Psychol Med (1998) 28:453-61. doi: 10.1017/ s0033291797005977

46. van Os J, Marcelis M, Germeys I, Graven S, Delespaul P. High expressed emotion: marker for a caring family? Compr. Psychiatry (2001) 42:504-7. doi: 10.1053/comp.2001.27899

47. Cruise RC, Sheeber LB, Tompson MC. Behavioral correlates of maternal expressed emotion in interaction tasks. J Fam. Psychol (2011) 25:781-4. doi: 10.1037/a0024699

48. O’Brien MP, Zinberg JL, Bearden CE, López SR, Kopelowicz A, Daley M, et al. Parent attitudes and parent adolescent interaction in families of youth at risk for psychosis and with recent-onset psychotic symptoms. Early Interv. Psychiatry (2008) 2:268-76. doi: 10.1111/j.1751-7893.2008.00088.x

49. O’Brien MP, Zinberg JL, Ho L, Rudd A, Kopelowicz A, Daley M, et al. Family problem solving interactions and 6-month symptomatic and functional outcomes in youth at ultra-high risk for psychosis and with recent onset psychotic symptoms: a longitudinal study. Schizophr Res (2009) 107:198205. doi: 10.1016/j.schres.2008.10.008

50. McCarty CA, Lau AS, Valeri SM, Weisz JR. Parent-Child interactions in relation to critical and emotionally overinvolved expressed emotion (EE): is ee a proxy for behavior? J Abnorm Child Psychol (2004) 32:83-93. doi: 10.1023/B:JACP.0000007582.61879.6f 
51. Mueser KT, Bellack AS, Wade JH, Sayers SL, Tierney A, Haas G, et al. Expressed emotion, social skill, and response to negative affect in schizophrenia. J Abnorm Psychol (1993) 102:339-51. doi: 10.1037//0021-843x.102.3.339

52. Strachan AM, Leff JP, Goldstein MJ, Doane JA, Burtt C. Emotional attitudes and direct communication in the families of schizophrenics: a cross-national replication. Br J Psychiatry (1986) 149:279-87. doi: 10.1192/bjp.149.3.279

53. Hubschmid T, Zemp M. Interactions in high- and low-EE families. Soc Psychiatry Psychiatr Epidemiol (1989) 24:113-9. doi: 10.1007/bf01788635

54. Hahlweg K, Doane J, Goldstein M, Neuchterlein K, Magana A, Mintz J, et al. Expressed emotion and patient interaction in families of recent onset schizophrenia. J Consult Clin Psychol (1989) 57:11-8. doi: 10.1037//0022006x.57.1.11

55. Mehl MR, Conner TS. Handbook of research methods for studying daily life. New York: Guilford Press (2012).

56. Vasconcelos e Sa D, Wearden A, Hartley S, Emsley R, Barrowclough C. Expressed Emotion and behaviourally controlling interactions in the daily life of dyads experiencing psychosis. Psychiatry Res (2016) 245:406-13. doi: 10.1016/j.psychres.2016.08.060

57. Wiedemann G, Rayki O, Feinstein E, Hahlweg K. The family questionnaire: development and validation of a new self-report scale for assessing expressed emotion. Psychiatry Res. (2002) 109:265-79. doi: 10.1016/s0165-1781(02)00023-9

58. Domínguez-Martínez T, Vainer E, Massanet MA, Torices I, Jané M, Barrantes-Vidal N. The need-adapted integrated treatment in Sant Pere Claver-Early Psychosis Program (SPC-EPP) in Barcelona, Spain. Salud. Ment. (2011) 34:517-24.

59. Yung AR, Yuen HP, Mcgorry PD, Phillips LJ, Kelly D, Dell'olio M, et al. Mapping the onset of psychosis: The Comprehensive Assessment of At-Risk Mental States. Aust N. Z. J Psychiatry (2005) 39:964-71. doi: 10.1080/j.1440-1614.2005.01714.x

60. Schultze-Lutter F, Addington J, Ruhrmann S, Klosterkötter J. Schizophrenia proneness instrument-adult version (SPI-A). Rome: Giovanni Fioriti (2007).

61. American Psychiatric Association. Diagnostic and Statistical Manual of Mental Disorders: DSM-IV-TR. Washington, DC: American Psychiatric Association (2002).

62. First MB, Spitzer RL, Gibbon M, Williams JB. Structured clinical interview for DSM-IV Axis I Disorders-Patient ed. (SCID-I/P, Version 2.0). New York: Biometrics Research Department (1995).

63. Burgin CJ, Silvia PJ, Eddington KM, Kwapil TR. Palm or Cell? Comparing personal digital assistants and cell phones for experience sampling research. Soc Sci Comput Rev (2013) 31:244-51. doi: 10.1177/0894439312441577

64. Kimhy D, Myin-Germeys I, Palmier-Claus J, Swendsen J. Mobile assessment guide for research in schizophrenia and severe mental disorders. Schizophr Bull (2012) 38:386-95. doi: 10.1093/schbul/sbr 186

65. Cohen JA. A Power Primer. Psychol Bull (1992) 112:155-9. doi: 10.1093/ schbul/sbr186

66. Muthén LK, Muthén BO. Mplus user's guide, sixth ed. Los Angeles: Muthén \& Muthén (1998-2010).

67. Bolger N, Laurenceau JP. Intensive longitudinal methods: an introduction to diary and experience sampling research. New York: Guilford Press (2013).

68. Nezlek JB. Multilevel modeling analyses of diary-style data. In: Mehl MR, Conner TSeditors. Handbook of research methods for studying daily life. Guilford Press (2012). p. 257-383.
69. Koutra K, Economou M, Triliva S, Roumeliotaki T, Lionis C, Vgontzas AN. Cross-cultural adaptation and validation of the Greek version of the Family Questionnaire for assessing expressed emotion. Compr. Psychiatry (2014) 55:1038-49. doi: 10.1016/j.comppsych.2014.02.017

70. Sepúlveda AR, Anastasiadou D, Rodríguez L, Almendros C, Andrés P, Vaz F, et al. Spanish validation of the Family Questionnaire (FQ) in families of patients with an eating disorder. Psicothema (2014) 26:321-7. doi: 10.7334/ psicothema2013.310

71. Hooley JM, Hiller JB. Personality and expressed emotion. J Abnorm Psychol (2000) 109:40-4. doi: 10.103W002I-843X. 109.1.40

72. Wasserman S, De Mamani AW, Suro G. Shame and guilt/self-blame as predictors of expressed emotion in family members of patients with schizophrenia. Psychiatry Res (2012) 196:27-31. doi: 10.1016/j.psychres.2011. 08.009

73. Bland R, Darlington Y. The nature and sources of hope: perspectives of family caregivers of people with serious mental illness. Perspect Psychiatr Care (2002) 38:61-8. doi: 10.1111/j.1744-6163.2002.tb00658.x

74. Tseng WS, Lu QY, Yin PY. Psychotherapy for the Chinese: Culture considerations. In: Lin TY, Tseng W, Yeh EHeditors. Chinese societies and mental health. Oxford University Press (1995). p. 281-94.

75. Gupta N, Mohanty S. Relationship of burden and social support with expressed emotion in spouses of persons with schizophrenia. J Indian Acad Appl Psychol (2016) 42:172-8.

76. Leff J, Vaughn C. Expressed Emotion in Families: its significance for Mental Illness. New York, NY: Guilford Press (1985).

77. Hooley JM. Expressed emotion and depression: interactions between patients and high-versus low-expressed-emotion spouses. J Abnorm Psychol (1986) 95:237-46. doi: 10.1037//0021-843x.95.3.237

78. Simoneau TL, Miklowitz DJ, Saleem R. Expressed emotion and interaction patterns in families of bipolar patients. J Abnorm Psychol (1998) 107:497507. doi: 10.1037//0021-843x.107.3.497

79. Hox J. Multilevel analysis: Techniques and applications. Mahwah, NJ: Erlbaum Associates (2002).

80. Myin-Germeys I, Klippel A, Steinhart H, Reininghaus U. Ecological momentary interventions in psychiatry. Curr Opin Psychiatry (2016) 29:25863. doi: $10.1097 /$ YCO.0000000000000255

81. Hinojosa-Marqués L. Family environment in early psychosis: In search of the psychological mechanisms underlying the manifestation of expressed emotion in at-risk and onset stages of psychosis. [doctoral thesis]. Barcelona (Spain): Universitat Autònoma de Barcelona (2018).

Conflict of Interest: The authors declare that the research was conducted in the absence of any commercial or financial relationships that could be construed as a potential conflict of interest.

Copyright $\odot 2019$ Hinojosa-Marqués, Dominguez-Martínez, Kwapil and Barrantes-Vidal. This is an open-access article distributed under the terms of the Creative Commons Attribution License (CC BY). The use, distribution or reproduction in other forums is permitted, provided the original author(s) and the copyright owner(s) are credited and that the original publication in this journal is cited, in accordance with accepted academic practice. No use, distribution or reproduction is permitted which does not comply with these terms. 